\title{
PENGARUH GROWTH RATE, KANDUNGAN NITRAT DAN INTENSITAS CAHAYA TERHADAP PRODUKTIVITAS BIOMASSA OLEH MIKROALGA CHLAMYDOMONAS sp
}

\author{
Rufaida Nur Rostika \\ Universitas Pandanaran \\ Jl. Banjarsari Barat No. 1, Pedalangan, Banyumanik, Semarang \\ email: fida.rostika@gmail.com
}

\begin{abstract}
Abstrak
Mikroalga Chlamydomonas sp dapat menghasilkan biomassa dengan cara mengubah $\mathrm{CO}_{2}$ dan dimanfaatkan sebagai penghasil energi biomassa. Pemberian laju alir dan konsentrasi gas $\mathrm{CO}_{2}$ yang bervariasi pada kultur Chlamydomonas sp menunjukkan adanya pengaruh terhadap growth rate dan $\mathrm{pH}$ pada masa kultivasi. Growth rate mikroalga Chlamydomonas sp mulai terbentuk secara maksimal dan produktivitas biomassa meningkat pada laju alir $\mathrm{CO}_{2} \quad 0,013$ 1/lmin sampai dengan 0,022 1/lmin. Pengaruh kandungan nitrat menyebabkan $\mathrm{pH}$ dapat menjadi asam maupun basa, dengan konsentrasi $\mathrm{CO}_{2}$ ditambah maka nitrat berlebih sehingga media kultivasi menjadi basa dan produktivitas biomassa meningkat. Kandungan nitrat tertinggi pada konsentrasi $\mathrm{CO}_{2} 30 \%$ dan $40 \%$. Laju pertumbuhan dan produktivitas mikroalga cenderung naik pada kondisi terang atau pencahayaan maksimal, sedangkan cenderung konstan pada kondisi gelap. Perlakuan penelitian terhadap Chlamydomonas sp dilakukan pada reaktor buble coloumn dan tubular dengan 6 liter medium kultur pada suhu $28^{\circ} \mathrm{C}$ dan tekanan atmosferik.
\end{abstract}

Kata kunci: Mikroalga, chlamydomonas sp, biofiksasi $\mathrm{CO} 2$, biogas, growth rate, kandungan nitrat, intensitas cahaya

\begin{abstract}
Microalgae Chlamydomonas sp can produce biomass by changing CO2 and used as an energyproducing biomass. The provision of gas flow rate and the concentration of CO2 varies in Chlamydomonas sp culture shows the influence of the growth rate and $\mathrm{pH}$ during cultivation. Growth rate of microalgae Chlamydomonas sp began to form maximal biomass and productivity increases in CO2 flow rate of 0,013 l / Lmin up to $0.022 \mathrm{l} / \mathrm{Lmin}$. Effect of nitrate content causes the $\mathrm{pH}$ can be acidic or alkaline, with a CO2 concentration of nitrate plus the excess so that the cultivation medium becomes alkaline and increased biomass productivity. The highest nitrate at a concentration of $30 \% \mathrm{CO} 2$ and 40\%. Microalgae growth rate and productivity tends to rise in bright conditions or maximum illumination, while relatively constant in dark conditions. Treatment studies of Chlamydomonas sp performed on coloumn and tubular bubble reactor with 6 liters of culture medium at a temperature of $280 C$ and atmospheric pressure.
\end{abstract}

Keywords: Microalgae, Chlamydomonas sp, biofiksasi CO2, biogas, growth rate, nitrate, light intensity

\section{PENDAHULUAN}

Dalam upaya mengurangi ketergantungan terhadap bahan bakar minyak pemerintah telah menerbitkan Peraturan Presiden Republik Indonesia nomor 5 tahun 2006 tentang kebijakan energi nasional untuk mengembangkan sumber energi alternatif sebagai pengganti bahan bakar minyak. Kebijakan tersebut menekankan pada sumber daya yang dapat diperbaharui sebagai alternatif pengganti bahan bakar fosil. Salah satu sumber energi alternatif yang saat ini banyak dikembangkan adalah biogas.

Biogas dapat diproduksi dari kotoran hewan, jerami ataupun tanaman lain yang mengandung $\mathrm{C} / \mathrm{N}$ tinggi. Untuk dapat 
digunakan sebagai bahan bakar alternatif, biogas harus dimurnikan dari gas $\mathrm{CO}_{2}$ dan $\mathrm{H}_{2} \mathrm{~S}$ sehingga nilai kalor biogas meningkat. Saat ini kandungan gas methane yang ada di biogas yaitu $40-60 \%$ dan hal ini setara dengan 18-21 MJ/m ${ }^{3}$ (4800-6900 kkal $/ \mathrm{m}^{3}$ ). Hal ini masih jauh lebih rendah dibandingkan dengan nilai kalor gas methane murni yaitu $9000 \mathrm{kkal} / \mathrm{m}^{3}$ Nurhasanah et al, 2006). Melalui proses pemurnian dengan cara penyerapan gas $\mathrm{CO}_{2}$ dan $\mathrm{H}_{2} \mathrm{~S}$ maka kandungan $\mathrm{CH}_{4}$ dalam biogas akan meningkat mendekati gas $\mathrm{CH}_{4}$ murni. Sebagai acuan bahwa $10 \%$ gas $\mathrm{CH}_{4}$ setara dengan $1 \mathrm{kWh} / \mathrm{m}^{3}$. Di lain pihak di ketahui juga bahwa 1,5-2 $\mathrm{m}^{3}$ biogas akan setara dengan $1 \mathrm{~L}$ bahan bakar solar diesel. Dengan pemurnian biogas dari $\mathrm{CO}_{2}$ dan $\mathrm{H}_{2} \mathrm{~S}$ maka diharapkan bahwa nilai kalor biogas akan meningkat dan energi yang dihasilkan lebih besar

Pemurnian menggunakan mikroalga merupakan suatu teknologi yang inovatif dan ekonomis karena mikroalga tersedia di alam dengan berbagai macam jenis spesiesnya. Dengan kemampuan mengkonsumsi karbon yang tinggi mikroorganisme ini sangat potensial untuk penyerap gas $\mathrm{CO}_{2}$ di biogas. Selain itu perlu dianalisa proses biofiksasi $\mathrm{CO}_{2}$ oleh mikroalga agar diperoleh hasil konversi ke biomassa yang tinggi. Dengan teknologi ini maka diharapkan diperoleh biogas dengan nilai kalor tinggi dan suatu paket teknologi yang ramah lingkungan merupakan target utama penelitian ini.

\section{METODE PENELITIAN}

Produksi biomassa Chlmydomonas $s p$ dilakukan pada kondisi operasi suhu $28^{\circ} \mathrm{C}$, tekanan atmosferik, variabel laju alir gas $\mathrm{CO}_{2}$ 0,031 $1 / 1 \mathrm{~min}-0,071 \mathrm{l} / 1 \mathrm{~min}$ dan konsentrasi gas $\mathrm{CO}_{2} 10 \%$ volume - $40 \%$ volume. Reaktor yang digunakan adalah jenis buble coloumn pada percobaan konsentrasi $\mathrm{CO}_{2} \quad 10 \%$ volume dan $20 \%$ volume seperti pada gambar 1 , dan reaktor tubular pada percobaan konsentrasi $\mathrm{CO}_{2}$ $30 \%$ volume dan $40 \%$ volume seperti pada gambar 2. Medium kultur yang digunakan sebanyak 6 liter dengan pencahayaan 4 lampu Philip masing-masing berdaya listrik $20 \mathrm{~W}$.

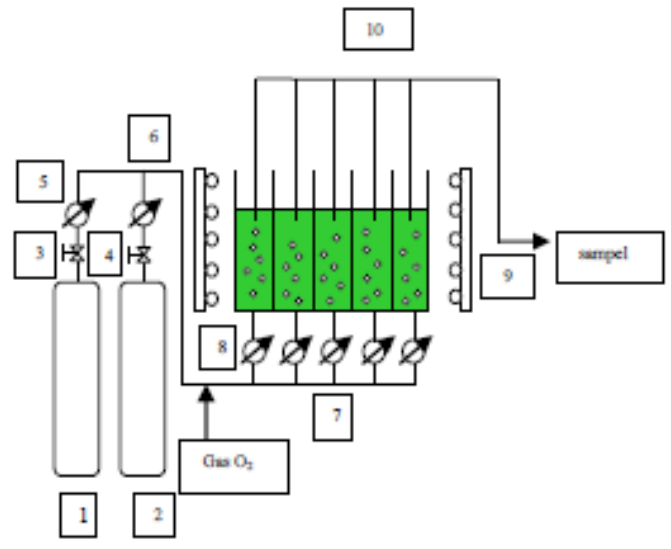

Gambar 1.

Rangkaian alat penelitian untuk konsentrasi gas $\mathrm{CO} 210 \%$ volume dan $20 \%$ volume, 1 . Tabung gas N2; 2 . Tabung gas $\mathrm{CO} 2 ; 3$. Valve tabung gas $\mathrm{N} 2 ; 4$. Valve tabung gas $\mathrm{CO} 2 ; 5$. Flow meter tabung gas $\mathrm{N} 2 ; 6$. Flow meter tabung gas $\mathrm{CO} 2 ; 7$. Flow meter photobioreactor; 8. Photobioreactor jenis buble coloumn; 9. Lampu; 10. Hasil gas

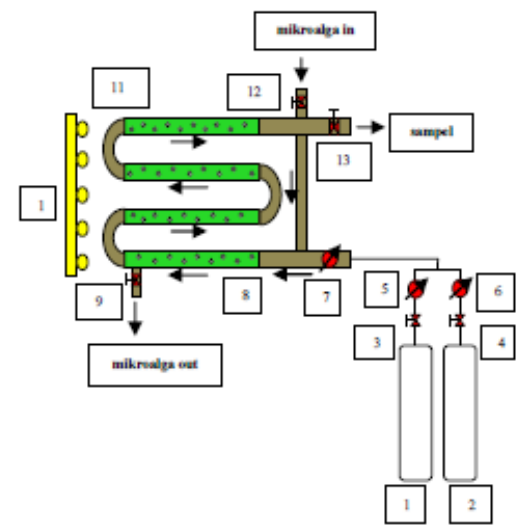

\section{Gambar 2.}

Rangkaian alat penelitian untuk konsentrasi gas $\mathrm{CO} 230 \%$ volume dan $40 \%$ volume, 1 . Tabung gas N2; 2 . Tabung gas $\mathrm{CO} 2 ; 3$. Valve tabung gas $\mathrm{N} 2 ; 4$. Valve tabung gas $\mathrm{CO} 2 ; 5$. Flow meter tabung gas N2; 6. Flow meter tabung gas CO2; 7. Flow meter photobioreactor; 8. Photobioreactor jenis tubular coloumn; 9. Valve keluaran mikroalga; 10. Lampu; 11. Elbow; 12. Valve masukan mikroalga; 13. Tempat pengambilan sampel 
Tahapan penelitian dimulai dengan membiakkan kultur murni Chlamydomonas $s p$ pada variasi laju alir gas $\mathrm{CO}_{2}$ dan variasi konsentrasi gas $\mathrm{CO}_{2}$ dengan tujuan untuk memperoleh data pertumbuhan mikroalga. Pada percobaan dengan konsentrasi $\mathrm{CO}_{2}$ $10 \%$ volume dan $20 \%$ volume tidak ditetapkan perbandingan rasio nutrient, sedangkan pada percobaan dengan konsentrasi $30 \%$ volume dan $40 \%$ volume menggunakan rasio nutrient dimana unsur $\mathrm{C}$ dijadikan limiting.

Setelah harga kultivasi mendekati 1 dengan membacanya di spektrofotometer pada panjang gelombang $680 \mathrm{~nm}$ (OD680) pembiakan kultur dihentikan dan dilakukan beberapa analisa seperti analisa hasil gas untuk mengetahui seberapa besar gas $\mathrm{CO}_{2}$ yang dapat diserap oleh mikroalga dengan rumus :

$$
\begin{aligned}
& \frac{\text { mol co2 yang tersarap }}{\text { mol co2 total }} \times 100 \% \\
& \mu(t) / \text { hari }=\ln \frac{x(t)}{X(0)} \\
& \text { produktivitas/hari }=\frac{\text { biomassa }}{\text { hari }}
\end{aligned}
$$

Analisa growth rate dan produktivitas mikroalga dengan rumus :

Disini $\mathrm{X}(\mathrm{t})$ adalah produksi biomassa pada waktu tertentu, sedangkan $\mathrm{X}(0)$ adalah nilai biomassa awal. Produktivitas dihitung dengan produksi biomassa pada konsentrasi tertentu dibagi dengan lama kultivasi.

Perbedaan perlakuan kondisi $\mathrm{pH}$ antara konsentrasi $\mathrm{CO}_{2} \quad 10 \%$ volume dan $20 \%$ volume yang diatur pada $\mathrm{pH}$ asam serta pada konsentrasi $\mathrm{CO}_{2} 30 \%$ volume dan $40 \%$ volume yang diatur pada $\mathrm{pH}$ basa sangat mempengaruhi hasil analisa.

\section{HASIL PENELITIAN DAN PEMBAHASAN}

1. Pengaruh Growth Rate dan
Produktivitas
Pada penelitian ini, growth rate akan
dibandingkan dengan produktivitas dari segi laju alir gas $\mathrm{CO}_{2}$ seperti terlihat dalam gambar 3.

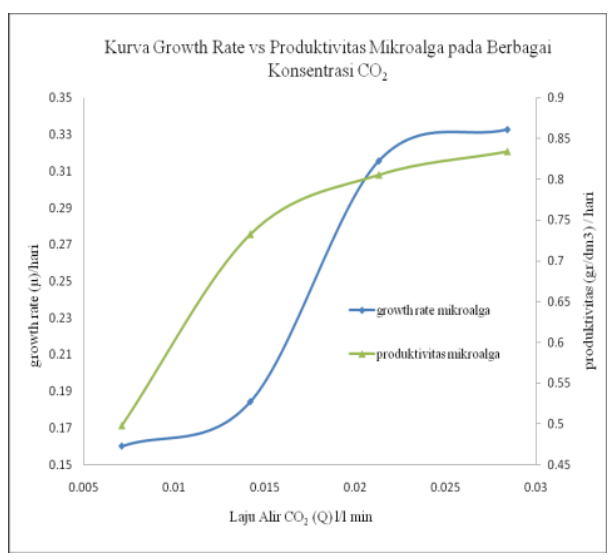

Gambar 3.

Kurva perbandingan growth rate dengan produktivitas mikroalga

Pada penelitian yang dilakukan oleh Winarno dkk (2007), produktivitas mikroalga jenis Chlamydomonas mencapai $0,494 \quad\left(\mathrm{gr} / \mathrm{dm}^{3}\right) /$ hari tanpa adanya penambahan nutrient. Sedangkan dari penelitian ini diperoleh produktivitas sebesar $0,834 \quad\left(\mathrm{gr} / \mathrm{dm}^{3}\right) /$ hari dengan penambahan nutrient. Hal ini membuktikan bahwa untuk meningkatkan produktivitas mikroalga diperlukan kondisi operasi yang optimal dan ketersediaan nutrient.

Laju pertumbuhan (growth rate) berbanding lurus dengan produktivitas karena dengan laju pertumbuhan yang optimal akan menghasilkan produktivitas yang optimal pula. Mikroalga yang mempunyai pertumbuhan baik akan lebih aktif mengkonversi $\mathrm{CO}_{2}$ menjadi biomassa sehingga produktivitas biomassa menjadi tinggi (Setiawan dkk, 2008).

Dari kurva terlihat bahwa pada konsentrasi $\mathrm{CO}_{2} \quad 10 \%$ volume dan $20 \%$ volume baik growth rate maupun produktivitas mengalami kenaikan, sedangkan pada konsentrasi $\mathrm{CO}_{2} \quad 30 \%$ volume dan $40 \%$ volume baik growth rate maupun produktivitas mulai konstan. Hal ini membuktikan bahwa senyawa karbonat $\left(\mathrm{HCO}_{3}{ }^{-}\right)$pada konsentrasi $10 \%$ volume dan $20 \%$ volume masih bisa dimanfaatkan oleh kultur untuk dirubah ke dalam biomassa dengan bantuan CA (Carbonic Anhydrase), 
sedangkan pada konsentrasi $\mathrm{CO}_{2} \quad 30 \%$ volume dan $40 \%$ volume, aktivitas CA sudah menurun sehingga efektivitas CA dalam memanfaatkan senyawa karbonat mulai berkurang.

2. Pengaruh Kandungan Nitrat terhadap $p H$

Semakin tinggi kerapatan sel pada medium kultur menyebabkan kondisi medium kultur meningkat tingkat kebasaannya ( $\mathrm{pH}$ semakin tinggi) dan hal itu menyebabkan peningkatan $\mathrm{CO}_{2}$ terlarut dalam medium kultur (Wijanarko dkk, 2007).

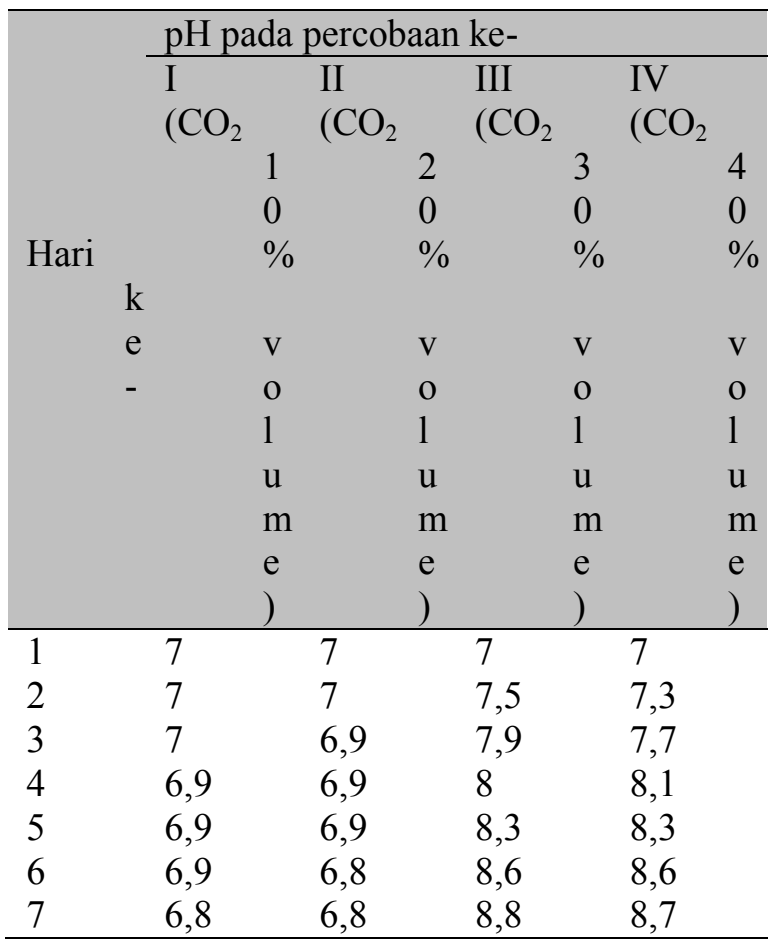

Tabel 1.

Nilai $\mathrm{pH}$ pada berbagai konsentrasi $\mathrm{CO} 2$ selama masa kultivasi

Pada tabel 1 terlihat bahwa pada percobaan 1 dan $2 \mathrm{pH}$ semakin turun (asam) karena medium kultur tidak tumbuh yang disebabkan oleh kandungan nitrat pada medium kultur kurang, sedangkan pada percobaan 3 dan $4 \mathrm{pH}$ semakin naik (basa) karena kandungan nitrat tercukupi (dibuat berlebih).

\section{Pengaruh Light and Dark Cycle}

Pada penelitian ini, cahaya sangat berpengaruh pada pembentukan biomassa seperti terlihat dalam gambar 4 .

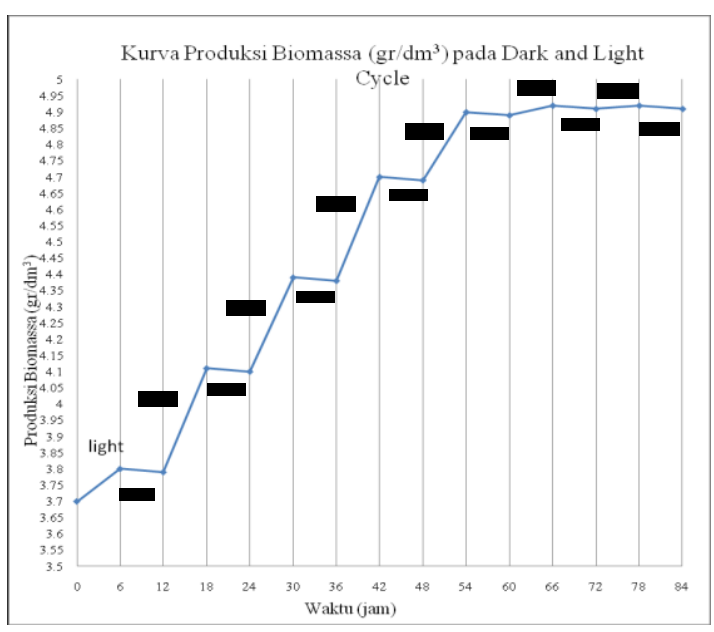

Gambar 4.

Kurva produksi biomassa pada dark and light cycle

Pada grafik di atas terlihat perbedaan laju pembentukan biomassa antara kondisi terang dan gelap. Pada kondisi gelap, mikroalga tidak melakukan proses sintesa biomassa melainkan mempertahankan hidupnya dengan cara melakukan respirasi sel sehingga medium kultur menjadi jenuh oleh senyawa karbonat yang tidak dimanfaatkan mikroalga. Hal ini menyebabkan pengurangan proses transfer gas $\mathrm{CO}_{2}$ ke dalam medium kultur (Wijanarko dkk, 2007).

\section{SIMPULAN}

1. Semakin tinggi laju alir gas $\mathrm{CO}_{2}$ maka growth rate mikroalga Chlamydomonas $s p$ akan mengalami kenaikan dan hal ini berbanding lurus dengan produktivitas biomassa pada masa kultivasi.

2. Pengaturan kondisi $\mathrm{pH}$ dan ketersediaan nutrient sangat mempengaruhi pertumbuhan media kultur, nitrat yang tercukupi (dibuat berlebih) dan kondisi $\mathrm{pH}$ yang basa akan meningkatkan pertumbuhan media kultur.

3. Tersedianya cahaya selama proses pertumbuhan media kultur sangat penting karena dengan cahaya yang cukup maka proses fotosintesis dimana $\mathrm{CO}_{2}$ dirubah menjadi senyawa karbonat 
yang kemudian dirubah menjadi biomassa dengan bantuan CA.

\section{DAFTAR PUSTAKA}

Setiawan, S., Sari, M., and Yuliusman. (2008). Mekanisme Absorbsi $\mathrm{CO}_{2}$ dengan Menggunakan Fitoplankton. Jurnal Ilmiah Bioteknologi. Volume (19):115-119.

Nurhasanah, A., Widodo, W. T., Asari, A., and Rahmarestia, E. (2006). Perkembangan Digester Biogas di Indonesia. Jurnal Pertanian. Volume (2):57.

Wijanarko, A., Hermansyah, H., Gozan, M., and Witarto, B.A. (2007). Pengaruh Pencahayaan Siklus Harian Terhadap Produksi Biomassa Chlorella vulgaris Buitenzorg Dalam Fotobioreaktor Kolom Gelembung. Jurnal Teknologi. Volume (1):58-65.

Winarno, B., Kuswandi, L., and Teguh, M. (2007). Absorbsi $\mathrm{CO}_{2}$ dengan Metode Wetted Wall Coloumn. Journal of Science and Technology. Volume (5):86. 